\title{
An integrated approach for road, transit design in a city logistic plan: a case study
}

\author{
D. Iannò ${ }^{2}$, A. Polimeni ${ }^{1}$ \& A. Vitetta ${ }^{1}$ \\ ${ }^{1}$ DIIES, Dipartimento di Ingegneria dell'Informazione, \\ delle Infrastrutture e dell'Energia Sostenibile, \\ Università degli Studi Mediterranea di Reggio Calabria, Italy \\ ${ }^{2}$ ATAM SpA, Italy
}

\begin{abstract}
In this paper, an integrated network and transit route design problem is analysed. A two-step design approach is proposed: first a trial transit route is designed using a greedy algorithm, second the road network is optimized taking into account, in the objective function, also of the route cost for freight. At the end of procedure, also the vehicle routing problem for city logistic distribution is designed using optimized road network and the reserved lanes for bus. The whole problem is formulated as a continuous-discrete problem, to consider both the topology and the link capacity.

Keywords: transit route design, public transport, road network design, genetic algorithm, freight distribution, vehicle routing problem.
\end{abstract}

\section{Introduction}

The main purpose of the Network Design Problem (NDP) is to generate the best optimal configurations of the network elements. The configurations are generated respect to a set of criteria. A mono or multi-objective approach (user, public manager and community) can be used, but the complexity of the problem does not allow the use of exact algorithms for real systems. In the particular case of urban area, the road infrastructure cannot be increased and the NDP define the optimal configuration of the system. With the NDP two sub-systems can be designed: the road network in terms of link directions and signals at the junctions, road and park fare; the transit network in term of routes, frequencies and tickets. In the literature, the two problems are studied separately. The city 
logistic distribution can be managed using the designed network for road and transit. This design aspect can be a component of a general framework able to simulate the transport interaction in an urban context [1] ant the behavioural aspects of urban freight distribution [2].

The NDP is classified, in consolidated literature, relating to the variables involved in the problem. Following this approach, the reported literature is divided into problem with discrete, continuous and mixed variables. In discrete field, can be reported the works [3-10]. In continuous field, can be reported the works [11-20]. In mixed field, can be reported the works [21-25].

In relation to the NDP for transit system, three main problems are considered: the route, the frequency and the scheduling design. This paper focuses the attention on the first class of problem. A general review of these methods are reported in [26-29] that are pioneer works on this topic. The routes are generated using heuristics or metaheuristics. It generates the routes starting from the best links on the shortest path; starting from these links, the route increases adding links in relation to a set of constraints. In the same heuristic or in a second level heuristic, the best frequency, for the lines inserted in the optimal routes, are defined. The best frequency is evaluated starting from the maximum flow on the lines and on the cost for line management. Some of the first papers containing a general method for route and frequency design, simulation of user behaviour, are [30, 31].

In most cases, the NDP for road and transit system are treated separately. In this paper, a formulation trying to link the two problems is proposed. The result is a two stages problem, road network and transit route design (Figure 1), with the extension to city logistic distribution.

The solution procedures proposed to solve the two separate problems are both heuristic.

In this paper, the original contributions are as follows:

- a mixed (discrete and continuous variables) network design problem is defined;

- the network design problem is connected with the transit design problem and city logistic distribution.

The paper is structured in the following sections. In section 2 the general model is proposed and in section 3 a solution algorithm is presented. Section 4 discusses some numerical examples for real system. Some conclusions future developments are reported in section 5 .

\section{Models}

Considering the model structure a network design model is defined by:

- an objectives function that is a measure of the criteria to minimize or maximize, depending on a set of design (or control) variables;

- a set of design variables that represents the network configurations;

- a set of technical (e.g. network connection, signals, number of lanes, number of bus), economic (e.g. monetary budget), normative (e.g. maximum CO emission), behavioural constraints. 
The behavioural constraint simulates the demand-supply interaction. Very often, considering the level of planning in the NDP, the model is considered with un-elastic demand.

The model proposed (Fig. 1) integrates the route design sub-model for transit system and the network and route design sub-model for road, freight and transit system.

The problem is solved in two sequential sub-models:

1) the Route design model, starting from the transit demand, the objectives and the constrains, generates the trial routes for transit system; the road supply is fixed and the routes for transit are design variable;

2) the Network and route design models, starting from the road and transit demand, the objectives and the constrains, generates the optimized network for road and the optimized routes for transit; the road supply and the routes for transit are design variables. The city logistic distribution is designed at the end, on the optimized network with the solution of a VRP (Vehicle Routing Problem); it generates the freight routes.

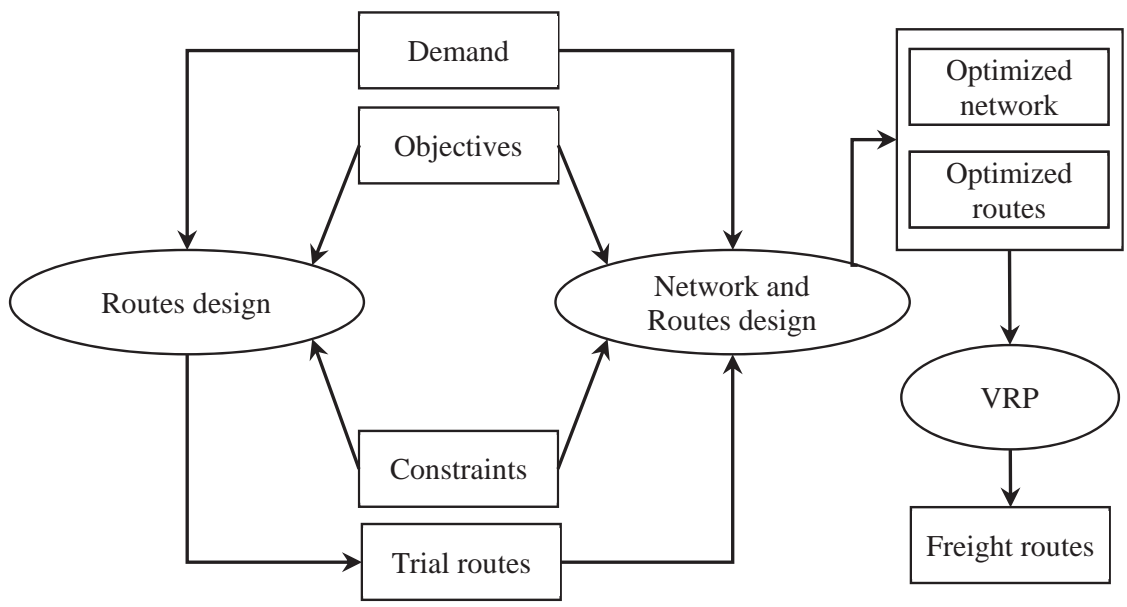

Figure 1: General approach.

Equation (1) reports the general formulation of the monocriterion problem.

$$
\min _{y, f} z(f, y)
$$

subject to technical, economic, normative, behavioural constraints where:

$z$ is the objective function;

$f$ is the link flow vector in the multimodal (road and transit) network that contain

- a link flow vector $\mathbf{f}^{(\mathrm{r})}$ for road;

- $\quad$ a link vector $\mathbf{f}^{(t)}$ for transit;

- a link vector $\mathbf{f}^{(\mathrm{f})}$ for freight; 
$\boldsymbol{y}$ is the configuration vector that contains

- $\quad$ a sub-vector $\mathbf{y}^{(1)}$ of configuration variables relative to the junction setting;

- $\quad$ a sub-vector $\mathbf{y}^{(2)}$ of configuration variables relative to the link layout;

- a sub-vector $\mathbf{y}^{(3)}$ of configuration variables relative to the transit routes layout;

- a sub-vector $\mathbf{y}^{(4)}$ of configuration variables relative to the freight routes layout.

In the whole formulation the objective function can be formulated as:

$$
\begin{gathered}
\mathbf{z}(\boldsymbol{f}, \boldsymbol{y})=\mathbf{z}_{1}\left(\boldsymbol{f}^{(t)}, \boldsymbol{y}^{(3)}\right)+\alpha_{1} \cdot \mathbf{z}_{2}\left(\boldsymbol{f}^{(r)}, \boldsymbol{y}^{(1)}, \boldsymbol{y}^{(2)}, \boldsymbol{y}^{(3)}\right) \\
+\alpha_{2} \cdot \mathbf{z}_{3}\left(\boldsymbol{f}^{(f)}, \boldsymbol{y}^{(1)} \boldsymbol{y}^{(2)}, \boldsymbol{y}^{(3)}, \boldsymbol{y}^{(4)}\right)
\end{gathered}
$$

where

- $\quad \alpha_{1}, \alpha_{2}$ are weights;

- $\quad \mathbf{z}_{1}$ is the cost for the transit users and system manger;

- $\quad z_{2}$ is the cost for the road users and system manger;

- $\mathbf{z}_{3}$ is the cost for the freight system.

The problem, solved with three sequential sub-models, is reported in details in Fig. 2.

The first sub-model is related to route design. The output of the first submodels (that is the input of the second sub-model) is the trial transit routes. It represent the first tentative route transit network to be improved in the second sub-model, together with the road network. Note that in this sub-model the objective function is $\mathbf{z}_{1}$.

The second sub-model is related to network and route design. The output of the second sub-models is the best road network and transit route. In this submodel, the objective function is $\mathbf{z}_{1}+\alpha_{1} \cdot \mathbf{z}_{2}$, to take into account both the transit and the road network system.

In the two sub-models the objectives and the technical and external constraints are in common. In relation to the behavioural constraints:

- $\quad$ the first sub-model considers the transit demand, the feasible road network, in a transit simulation model;

- $\quad$ the second sub-model considers the transit and cars demand, the trial transit routes generated with the first sub-model, the road network, in a transit and car simulation model.

The third sub-model has as input the optimized road network and the transit routes; solving a Vehicle Routing Problem (VRP) generates the freight routes. The objective function is $\mathbf{z}_{1}+\alpha_{1} \cdot \mathbf{z}_{2}+\alpha_{2} \cdot \mathbf{z}_{3}$. 


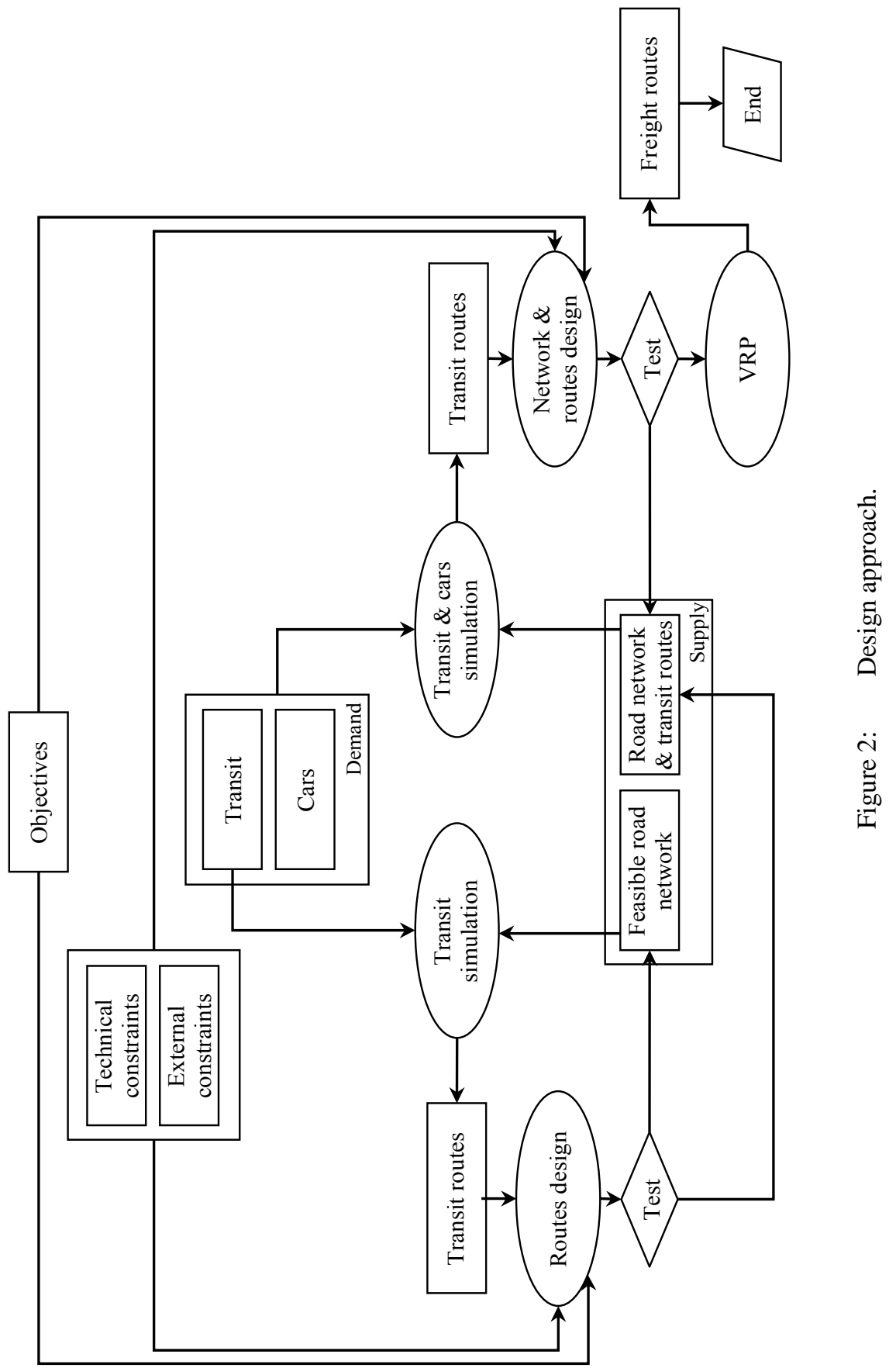




\section{Procedure}

In this Section, the procedures proposed to solve the problem discussed in section 2 are reported.

In section 3.1, the algorithm to design the trail transit route(s) is reported; in section 3.2, the algorithm to design the road network is reported. In section 3.3, the algorithm to design vehicle routes is reported.

\subsection{Transit routes design}

The transit routes design approach allows designing the transit routes starting from the feasible network. In general, a solution includes some transit routes.

The transit routes design [32] involves two phases:

i) design of the potential routes;

ii) extraction of the final set of routes.

i) The design of the potential routes consists of three main parts:

i.1) individuate the last stations;

i.2) extract the feasible network;

i.3) build the transit routes.

i.1) The last stations are localized considering the positions able to favourite the transhipment, favourite the inter-modality, favourite the accessibility.

i.2) The feasible network extraction is made starting from the road network and eliminating some links considering specific criteria. The criteria are related to geometry (links and junctions) and law constraints (circulation plan, car park, bus number).

i.3) The algorithm applied to build the transit routes is an heuristic, based on a greedy search. At each iteration, a set of three links (waiting, boarding, alighting) is added, optimizing the objective function. To establish the point where insert the new links, two cases are considered: 1 ) in the current solution there are some partial transit routes; 2) all the transit routes in the solution are definitive. In first case, the set of three links is added considering only the forward star of the initial node of the routes or the backward star of the final node. In second case, the set of three links is added considering all the links in the feasible network.

ii) The extraction of the final set of transit routes is performed considering the characteristics of designed lines, as length (or time) and maximum frequency.

\subsection{Road network design}

The transit routes contain some bus stops to allow the users up/down. The stops can be grouped in main stops, considering those stops characterized by higher flow of boarding/alighting users. In road network design approach, the transit line is constrained to go from those main stops. The road network design optimizes road link layout, junctions, reserved transit and freight lanes, transit 
route. Note that the road network design does not change the main stop sequence, but could design also the path between a main stop and the next.

The algorithm implemented to solve the link layout is based on genetic algorithm proposed in Cantarella et al. [21].

Starting from an initial population, the genetic algorithm evolves for a fixed number of iterations optimizing the objective function. In our approach, each element in the population is a feasible solution, since respects all the constraints of the problem.

The main steps of a genetic algorithm are [33]:

- $\quad$ selection: to extract the solutions involved in the next steps (i.e. an approach is the roulette tournament);

- $\quad$ crossover: to evolve the population through the generations;

- mutation: to introduce a perturbation in some solutions (the target is to modify the search in the solution space).

\subsection{Freight routes design}

The freight routes design approach allows designing the freight routes starting from the optimized road network and considering the reserved lanes (if any) for transit lines. To optimize the routes it is necessary to solve a VRP. The VRP is a very hard combinatorial problem that, in most of cases, must be solved with a heuristic approach. The heuristic choice in this paper is a genetic algorithm, as proposed in [33]. The algorithms optimizes the routes minimizing the total routes cost.

\section{Experimentation}

The experiment was carried out in the city of Reggio Calabria (Italy), a city with a population of about 180,000 inhabitants.

The city of Reggio Calabria [34] occupies a surface of $275 \mathrm{~km}^{2}$ that places it by extension at the first places among the Italian cities. It extends in a long and narrow manner, stretched along the ionic shoreline for approximately $30 \mathrm{~km}$ between Bocale to the South and Gallico-Catona to North. Therefore, it does not have a central radial development characteristic of many cities, but a longitudinal development with the road network with a comb structure, with a number of incoming lines connecting the suburban areas and the villages on the mountain side to the main costal area. The main rail and road axis run along the coastline, and local and regional roads run from the mountain and connect on the costal motorway.

The railway line extends along the coast and altogether at the station of Reggio Calabria arrive around 150 trains/day (local and long distance).

The lines of extra-urban coaches offer transport services between Reggio Calabria and the cities and towns of the province and region with distances that are developed mostly along the SS 18 national road, the A3 Motorway and SS 106 national road and often offering a service in parallel with the railway track and service. 
Public transport in Reggio Calabria is managed by ATAM SpA (ATAM SpA: Azienda Trasporti per l'Area Metropolitana, Società per Azioni). It is performed by a bus fleet of 95 vehicles (urban service), for a total annual distance of 4,225,000 bus $\mathrm{x} \mathrm{km}$.

The program of urban services is based on the realization of a leading system of transport (main network) along the principal directories of traffic, in a position to connect the main centres of attraction (railway stations, port, airport, central business and commercial district, town centre, institutional buildings, stadium and sport centres, university campus). It is constituted from a high capacity line with high commercial speeds, defined from the analysis of the current mobility demand. The secondary network is constituted from lines that allow the most direct connection between the fractions and/or the suburban areas and the main interchange nodes, located on the edges of the central city area served from the main network, and the lines in the central area that serve as adduction shuttle to the main network.

The tariff plan provides integration of tariffs between the buses and the train is in the stations between Rosarno and Melito Porto Salvo. Each year the 40 lines provided in the plan transport, approximately 7,000,000 passengers.

\subsection{Transit route design}

In the current ATAM management plan, the line with high frequency and higher load application consists of a line that extends from north to south of the city and connects the main intermodal nodes (Airport, Botteghelle Terminal, Central Station, Lido Station, Port, Libertà Terminal) and the faculties of Architecture, Engineering and Agriculture (10,000 students and staff) located in the area of Feo di Vito.

Moreover, the line intercepts the demand generated by the presence of other major poles of attraction such as offices, institutions, shops, and shopping centers.

This the line characteristics: 40 bus stops, 21 kilometres, 4 bus/hour. The service is carried out, from 06.00 to 21.00 , by using 8 bus and 16 bus drivers.

The aim of the transit route design is, starting from a feasible network, to generate a main route subject to greater load.

The feasible network for Reggio Calabria (the starting point to build the graph of transit lines) has been identified considering only the infrastructural elements that allows the bus transit and eliminating all other (i.e. elements with low bend radius or reduced width).

For each link type (pedestrian, waiting, boarding, alighting, line) a cost function is defined.

ATAM has provided the demand matrix, recently updated through specific surveys and counts flow on the line.

The assignment on the feasible network allows identifying the link with greater flow, generating with the next iterations the route between Airport and University.

The objective function considered in this model is the component $z_{1}$ of equation (2). The generated route corresponds to 95\% at the actual route (Fig. 3). 


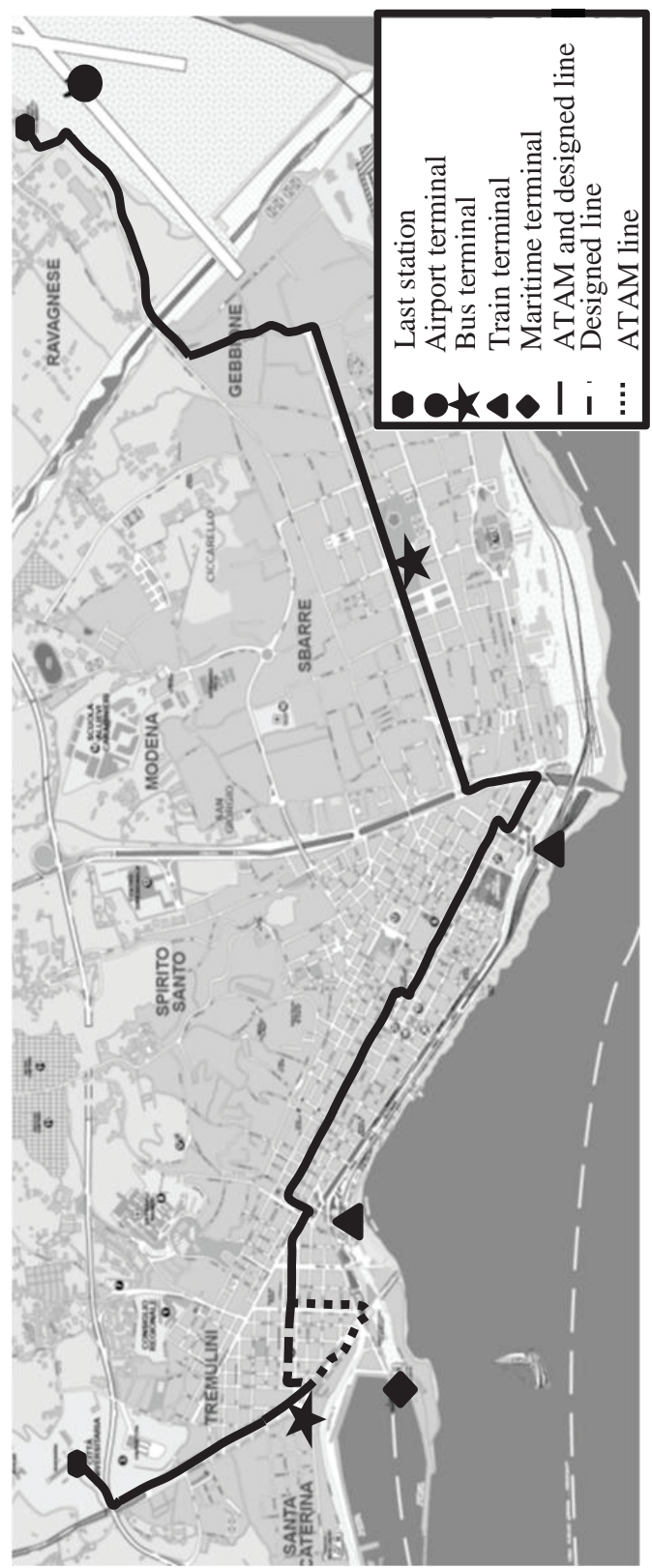

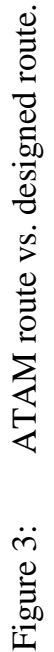


The differences concerning only in the links near to the maritime terminal. In the ATAM route, the links around the port are used to favourite the accessibility of the port with the airport and the university. The algorithms, instead, generate the route on links belonging on city centre with higher demand.

\subsection{Road network design}

The generated route with the algorithm proposed in section 3.1 is optimized in the phase of road network design. The location of the main bus stops, the output of the previous design level, is fixed. The path between two consecutive stops or the lane use (i.e. the lane is reserved for buses) are designed. The objective function (2) considers both the route cost (component $z_{1}$ ) and the road users cost (component $z_{2}$ ) that change changing the road network configuration. A preliminary application on the road network of Reggio Calabria shows that reserving some lanes to the transit routes (also usable for freight routes) increases (approximately 3\%) the cost for road users but decreases the cost for transit and freight routes (approximately 7\%). These preliminary results can mean the procedure is applicable in urban contexts to optimize transit and freight routes.

\section{Conclusions}

In this paper an approach to design transit routes and road network is reported. A general model is formulated to consider the correlation between transit routes and network design. The whole model is discussed analysing its components. Two heuristic algorithms are proposed to solve the problem: a greedy search to design the transit routes, genetic algorithms to design the road network. Future development regarding the application of the procedure in wider context (more transit lines) and optimize the order of bus stops and freight paths. Particular attention will be done to the reliability of travel time for transit routes, at moment not considered in this paper.

\section{Acknowledgements}

Partially supported by national MIUR under PRIN2009 grants n. 2009 EP3S42_001 and PRIN2008 grants n. 2008YEPPM3_002.

ATAM SpA is thanked for permission to use data and map by means of ing. Domenico Iannò.

\section{References}

[1] Russo F. \& Musolino G., A unifying modelling framework to simulate the Spatial Economic Transport Interaction process at urban and national scales. Journal of Transport Geography, 24, pp. 189-197, 2012. 
[2] Russo, F., Modeling behavioral aspects of urban freight movements. In Freight transport modeling (Ben-Akiva M. E., Meersman H. \& Van De Voode eds.), Emerald Group Publishing Limited, 2013.

[3] Billheimer J.W. \& Gray P., Network design with fixed and variable cost elements. Transportation Science, 7, pp. 49-74, 1973.

[4] Chen M. \& Alfa, A.S., A network design algorithm using a stochastic incremental traffic assignment approach. Transportation Science, 25(3), pp. 215 224, 1991.

[5] Foulds, L.R., A Multi-Commodity Flow Network Design Problem. Transportation Research Part B 15, 273-283, 1981.

[6] Gao, Z., Wu J. \& Sun, H., Solution algorithm for the bi-level discrete network design problem. Transportation Research B, 39, 479-495, 2005.

[7] Poorzahedy H. \& Abulghasemi F., Application of Ant System to network design problem. Transportation, 32, pp. 251-273, 2005.

[8] Herrmann J.W., Ioannou G., Minis I. \& Proth J.M, A dual ascent approach to the fixed-charge capacitated network design problem. European Journal of Operational Research, 95, 476-490, 1996.

[9] Solanky, R.S., J.K. Gorti \& Southworth F., Using decomposition in largescale highway network design with a quasi-optimization heuristic. Transportation Research B 32 (2), pp. 127-140, 1998.

[10] Kalafatas G. \& Peeta S., Planning for evacuation: insights from an efficient network design model. Journal of infrastructure systems, 15(1), 21-30, 2009.

[11] Webster F. W., Traffic signal settings. Road Research Technical Paper no. 39, 1958.

[12] Webster, F.V. \& Cobbe B.M., Traffic Signals. Road Research Laboratory Technical Paper 56, London, UK, 1966.

[13] Allsop, R.E., SIGCAP: A computer program for assessing the traffic capacity of signal-controlled road junctions. Traffic Engineering \& Control 17, 338-341, 1976.

[14] Gartner N.H., Area traffic control and network equilibrium. Traffic Equilibrium Methods, Lecture Notes in Economics and Mathematical Systems, 118, M. Florian, ed., Springer-Verlag, Berlin, pp. 274-297, 1976.

[15] Smith, M.J., The existence, uniqueness and stability of traffic equilibria. Transportation Research B, 13(4), 295-304, 1979.

[16] Sheffi Y. \& Powell W. B., Optimal signal setting over transportation networks. Transportation Engineering, 109(6), pp. 824-839, 1983.

[17] Meneguzzer C., An equilibrium route choice model with explicit treatment of the effect of intersections. Transportation Research B, 29, 329-356, 1995.

[18] Chiou, S.W., Optimal design of signal-controlled road network. Applied Mathematics and Computation, 189, 1-8, 2007.

[19] Marcianò, F.A., G. Musolino \& Vitetta A. (2010) Signal setting design on a road network: Application of a system of models in evacuation conditions. WIT Transactions on Information and Communication Technologies, 43 (part I), pp. 443-454. 
[20] Cantarella, G.E., P. Velonà, \& Vitetta A., Day-to-day dynamic network modeling and optimization. IEEE International Intelligent Transportation Systems Conference, ITSC 2011; pp. 2086-2092, 2011.

[21] Cantarella G.E., Pavone G. \& Vitetta A., Heuristics for urban road network design: lane layout and signal settings. European Journal of Operational Research, 175, pp. 1682-1695, 2006.

[22] Russo F. \& Vitetta A., A topological method to choose optimal solutions after solving the multi-criteria urban road network design problem. Transportation, 33, pp. 347-370, 2006.

[23] Poorzahedy H. \& Rouhani O.M., Hybrid meta-heuristic algorithms for solving network design problem. European Journal of Operational Research 182(2), pp. 578-596, 2007.

[24] Polimeni, A. \& Vitetta, A., A procedure for an integrated network and vehicle routing optimisation problem. Procedia - Social and Behavioral Sciences, 54, pp. 65-74, 2012.

[25] Polimeni, A. \& Vitetta, A., Joint network and route optimization in road evacuation. WIT Transactions on Ecology and the Environment, 155, pp. 1053-1065, 2011.

[26] Baaj, H. M. \& Mahmassani, H. S., Hybrid route generation heuristic algorithm for the design of transit networks. Transportation Research $C$, 3(1), pp. 31-50, 1995.

[27] Ceder A. \& Wilson N.H.M., Bus network design. Transportation Research B, 20(4), pp. 331-344, 1986.

[28] Ceder, Designing public transport network and routes. In Advanced modeling for transit operations and service planning, Lam and Bell (eds.), cap. 3, Pergamon Imprint, pp. 59-91, 2003.

[29] Lee Y.J. \& Vuchic V., Transit network design with variable demand. Journal of Transportation Engineering, 131(1), pp. 1-10, 2005.

[30] Nuzzolo A., Russo F. \& Crisalli U., Transit network modelling. The schedule-based dynamic approach, FrancoAngeli, Milano, 2003.

[31] Fusco G., Gori S. \& Petrelli M., An heuristic transit network design algorithm for medium size towns. Proceedings of the 13th Mini-EURO Conference, Bari, 2002.

[32] Russo F., Metodi per la progettazione dei sistemi di trasporto collettivo. Quaderno di dipartimento, QD-SD 1/10, 2010.

[33] Polimeni A., Russo F. \& Vitetta A., Demand and routing models for urban goods movement simulation. European Transport - Trasporti Europei, 46, pp. 3-23, 2010.

[34] Cirianni F. \& Iannò D., Good practices in public transport planning: competing modal choices and enforced transport policies. Proceedings of European Transportation Conference, Strasbourg, FR, 2004. 